\title{
Efeito do glutaraldeído na adsorção de extrato proteico da ipomoea batatas (l) lam na superficie de uma zeólita analcima
}

\section{(Effect of the glutaraldeide on the adsorption of proteic extract of the ipomoea batatas (l) lam in analcime zeolite surface)}

\author{
A. C. S. Gondim, L. R. D. da Silva \\ Laboratório de Físico-Química de Minerais e Catálise \\ Departamento de Química Orgânica e Inorgânica, Universidade Federal do Ceará \\ C.P. 6002, Campus do Pici, Fortaleza, CE 60451-970 \\ lindomar@dqoi.ufc.br
}

\begin{abstract}
Resumo
A zeólita analcime $\left(\mathrm{Na}_{16} \mathrm{Al}_{16} \mathrm{Si}_{32} \mathrm{O}_{96} \cdot \mathrm{nH}_{2} \mathrm{O}\right)$ foi submetida a ataque ácido com $\mathrm{HCl}$ 0,25 mol.L-1 , seguido da funcionalização com glutaraldeído, foi imersa em extrato protéico obtido da polpa da batata-doce (Ipomoea Batatas (L) Lam), que tem em sua composição a enzima polifenol oxidase (PFO). As amostras foram submetidas a procedimentos de caracterização por microscopia eletrônica de varredura, espectroscopia na região do infravermelho com transformada de Fourier e termogravimetria.

Palavras-chave: zeólita analcima, glutaraldeído, polifenol oxidase, enzima.
\end{abstract}

Abstract

The analcime zeolite $\left(\mathrm{Na}_{16} \mathrm{Al}_{16} \mathrm{Si}_{32} \mathrm{O}_{96} . \mathrm{nH}_{2} \mathrm{O}\right)$ was treated with hydrochloric acid 0.25 mol. $\mathrm{L}^{-1}$, followed by the funcionalization with glutaraldehyde and immersed in the proteic extract obtained from gross extract of sweet potato pulp (Ipomoea Batatas (L) Lam), which presents in its composition the polyphenol oxidase enzyme (PPO). Other samples were submitted to the same procedure with characterizations by scanning electron microscopy, Fourier Transform Infrared spectroscopy and thermogravimetry.

Keywords: analcime zeolite, glutaraldehyde, polyphenol oxidase, enzyme.

\section{INTRODUÇÃO}

A partir das observações de Crönsted sobre o intumescimento da estilbita, em 1756, teve início um novo campo de aplicação dos silicatos naturais.

Em 1862 St. Claire Deville realizou a primeira síntese hidrotérmica a partir de rochas metamórficas, e a partir dos trabalhos de Weighel e Steinhoff sobre a seletividade da chabazita, McBain, em 1932, introduziu o termo peneiras moleculares [1].

Barrer em 1945 utilizou a chabazita para purificar gases [2]. No entanto, as zeólitas naturais já se mostravam insuficientes para o uso industrial, e com isso em 1950, surgiram as primeiras zeólitas sintéticas. A partir daí muitas outras foram sendo obtidas [3-10].

Devido a concentração de alumínio ser maior nas zeólitas naturais, e a estabilidade térmica estar relacionada à relação $\mathrm{Si} / \mathrm{Al}$, estas foram substituídas pelas sintéticas nas aplicações industriais [11-13].

$\mathrm{O}$ avanço da química de materiais tem influenciado o desenho de novos sensores analíticos, onde uma grande variedade de eletrodos de bio-reconhecimento é citada na literatura [14-16]. Os biossensores enzimáticos normalmente utilizados são os potenciométricos ou os amperométricos. Como exemplo, pode-se citar para o primeiro tipo a detecção de uréia no sangue. Para o segundo, a determinação de glicose, sendo que o primeiro sensor amperométrico baseado em enzimas oxidases para análise de glucose foi proposto por Clarck e Lyons, em 1962 [17].

Alguns tipos de substratos têm merecido mais atenção que outros, por se tratar de substâncias que oferecem grande risco à saúde pública, tais como os fenóis que são compostos aromáticos que podem conter além do grupo hidroxila, metila, amida, e os grupos sulfônicos ligados a radicais benzílicos. Estes compostos são poluentes do meio ambiente, e costumam ser detectados em efluentes como os das indústrias de refino de petróleo, farmacêutica, papel e celulose [18].

Devido os altos custos envolvidos na obtenção das enzimas, e dos descartes destas após sua utilização nos 
processos homogêneos, muitos esforços tem sido feitos no desenvolvimento de matrizes para esses catalisadores que tem apresentado algumas vantagens com relação ao uso em solução, como por exemplo, maior estabilidade e menor variação devido a interferentes [19-26].

Com o recente avanço das técnicas de imobilização de enzimas, o custo dos processos tem sido reduzido consideravelmente, pois permite a sua reutilização, o que não acontece com as enzimas em solução. Diversos métodos de imobilização são relatados [27], porém o sucesso da imobilização dependerá da escolha do suporte, pois poderá haver a desnaturação, e com isso a perda da enzima. A imobilização pode ser feita de diversas formas, incluindo adsorção física sobre suporte inorgânico poroso (ex. alumina), adsorção química em uma superfície como em pérolas de vidro ou em polímeros, sendo possível também, a co-polimerização entre a enzima e um monômero apropriado [20].

A partir dos resultados de atividade catalítica de enzima contida no extrato bruto da batata doce (Ipomoea Batatas (L) Lam), adsorvida na superfície da analcima descrita anterioremente [28], verificou-se a necessidade de um estudo do efeito do glutaraldeído sobre a superfície do suporte zeolítico e sua interação com o extrato protéico, no processo de adsorção.

\section{MATERIAIS E MÉTODOS}

\section{Adsorção de glutaraldeído na superficie da zeólita}

O suporte utilizado foi uma zeólita do tipo analcima, obtida por meio da reação de um caulim branco com álcalis em condições hidrotérmicas e pressão autógena [29]. Este foi submetido a troca-iônica com ácido clorídrico 0,25 mol.L $\mathrm{L}^{-1}$, em suspensão a $10 \% \mathrm{~m} / \mathrm{v}$ com agitação constante durante $2 \mathrm{~h}$, para gerar a acidez necessária à interação do suporte com o glutaraldeído.

Após a troca iônica para a obtenção da forma ácida a partir da sódica, a amostra obtida denominada H-ANA, da qual foi separada uma fração para análise de acidez, foi mistura a $20,0 \mathrm{~mL}$ de uma solução de glutaraldeído $5 \% \mathrm{v} / \mathrm{v}$ em 0,05 mol.L $\mathrm{L}^{-1}$ de tampão fosfato $\mathrm{pH} 7,0$, nas condições estabelecidas em [30]. O glutaraldeído foi escolhido por possibilitar ligações covalentes cruzadas muito estáveis e irreversíveis, permitindo ao material resistir a oscilações no $\mathrm{pH}$ e temperatura numa faixa ampla de valores. A amostra resultante $\mathrm{H}$-ANA/Glu foi lavada com tampão fosfato e seca em banho-maria a $50{ }^{\circ} \mathrm{C}$ sob vácuo; E tanto esta como a amostra H-ANA foram caracterizadas por espectroscopia no infravermelho em espectrofotômetro Perkin-Elmer em pastilhas de $\mathrm{KBr}$ a $2 \%$ m/m. A amostra H-ANA foi submetida à adsorção com amônia que foi carreada através de $100 \mathrm{mg}$ de amostra durante $2 \mathrm{~h}$, seguida da remoção do excesso com ar comprimido durante $4 \mathrm{~h}$.

Para a determinação do processo de degradação térmica, adicionou-se cerca de $500 \mathrm{mg}$ de zeólita contendo glutaraldeído no sistema TVA (Análise por termovolatilização) à temperatura ambiente com razão de aquecimento de $15^{\circ} \mathrm{C} / \mathrm{min}$ até o forno atingir $450^{\circ} \mathrm{C}$. A amostra foi deixada nessa temperatura durante uma hora, e a seguir resfriada e analisada por espectroscopia no infravermelho. Concomitantemente, foram realizadas análises termogravimétricas em um equipamento Shimadzu modelo TGA50, com fluxo de ar sintético de $50 \mathrm{~mL} \cdot \mathrm{min}^{-1}$, uma taxa de aquecimento de $10{ }^{\circ} \mathrm{C} \cdot \mathrm{min}^{-1}$, e $8 \mathrm{mg}$ de amostra.

Obtenção e adsorção do extrato protéico da polpa da batata-doce (Ipomoea Batatas (L) Lam) na superficie da zeólita

O extrato bruto utilizado foi obtido da polpa da batata doce (Ipomoea batatas (L) Lam) do qual foi extraído o extrato protéico contendo a enzima polifenol oxidase (PPO).

Uma suspensão obtida da homogeneização de $25 \mathrm{~g}$ de batata doce em tampão fosfato em $\mathrm{pH}$ 7,0 e contendo Polyclar ${ }^{\circledR}$ SB-100 (PVP) a $4{ }^{\circ} \mathrm{C}$, foi filtrada e centrifugada a $18000 \mathrm{~g}$ X $14000 \mathrm{rpm}$, durante $45 \mathrm{~min}$, mantendo-se a temperatura em $4{ }^{\circ} \mathrm{C}$. A concentração de proteínas foi determinada em triplicata de acordo com o método de Bradford [31]. Na adsorção das proteínas para cada $100 \mathrm{mg}$ de zeólita foram utilizados $10 \mathrm{~mL}$ de solução protéica, que permaneceram em contato por um período de 3 horas a $4{ }^{\circ} \mathrm{C}$, sob constante agitação. Em seguida as amostras foram lavadas com água deionizada até a completa remoção das proteínas não adsorvidas, e secas em estufa a $110^{\circ} \mathrm{C}$ durante uma noite. As amostras foram submetidas a análises espectroscópicas nas mesmas condições das anteriores, e microscópicas em um microscópio eletrônico de varredura Philips com as amostras tendo sido inseridas em porta-amostra de latão e fixadas com cola de prata, em seguida foram recobertas com vapor de carbono.

\section{RESULTADOS E DISCUSSÃO}

A analcime utilizada nesse trabalho, cuja preparação e caracterização já foram discutidas [29], possui estrutura cúbica de fórmula geral $\mathrm{NaAlSi}_{2} \mathrm{O}_{6} \cdot \mathrm{H}_{2} \mathrm{O}$, proposta por Nibou [32] e refinada por Yokomori e Pechar [33, 34], que devido ao sódio que ocupa $2 / 3$ das posições de troca, aliado aos tamanhos de cristais de cerca de $30 \mu \mathrm{m}$, tornam a analcima um material interessante para processos de adsorção.

A propriedade química mais importante das superfícies zeolíticas é, talvez, a razão $\mathrm{Si} / \mathrm{Al}$, a partir da qual se tem uma definição de sua capacidade adsorvente, visto que esta razão será sempre superior a 1 , pois segundo a regra de Lowestein [35], na estrutura de uma zeólita não pode haver dois tetraedros de alumínio vicinais, e com isso haverá um desequilíbrio das cargas, pois o silício é tetravalente e o alumínio trivalente. Esta diferença poderá ser compensada pelos contra-íons, sendo o sódio e o hidrogênio os mais utilizados [36-38].

Analisando o espectro de infravermelho (Fig. 1) nota- 
se que após a troca-iônica de sódio por hidrogênio, e subseqüente adsorção de amônia, identifica-se uma banda em $1678 \mathrm{~cm}^{-1}$ atribuída às ligações N-H em sítios ácidos de Lewis. Essa acidez foi decisiva na condensação do espaçador (glutaraldeído), visto que, tentativas anteriores sem ativação ácida não apresentaram bons resultados.

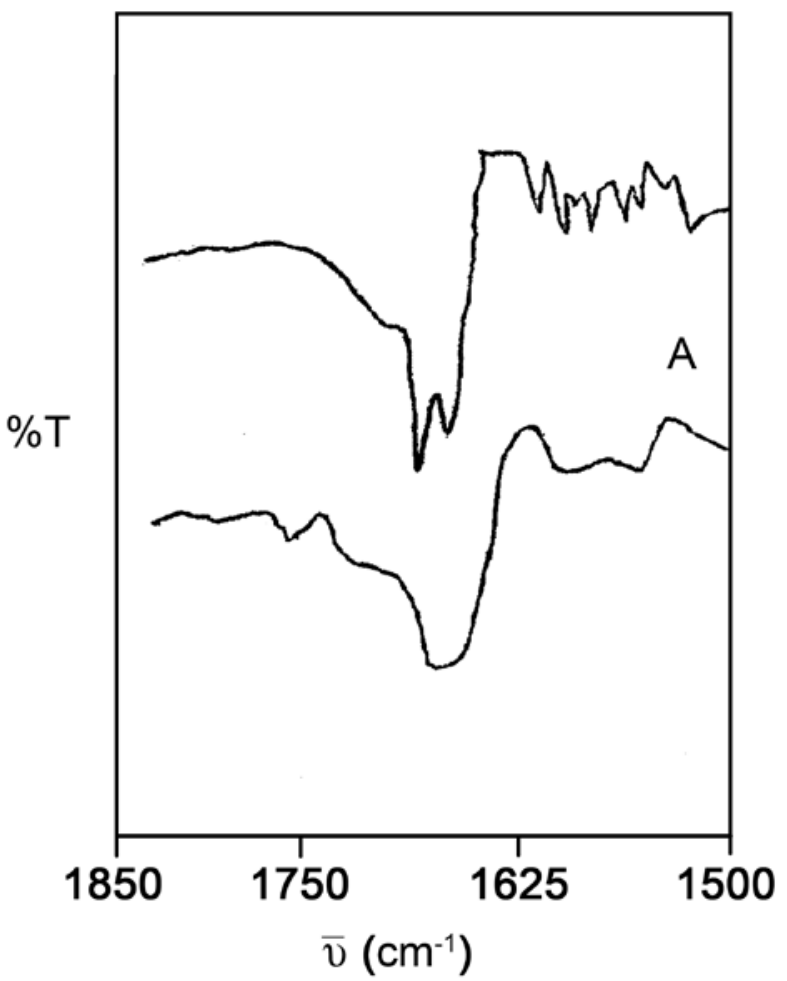

Figura 1: Espectros na região do infravermelho da zeólita analcima. (A) $\mathrm{Na}^{+}$-ANA, (B) $\mathrm{NH}_{4}^{+}$-ANA.

[Figure 1: FTIR spectra of analcime zeolite. (A) $\mathrm{Na}^{+}-\mathrm{ANA}$, (B) $\mathrm{NH}_{4}^{+}-\mathrm{ANA}$.]

Após a adsorção do glutaraldeído, observa-se no espectro de infravermelho (Fig. 2) que a banda característica da carbonila de aldeído $(v \mathrm{C}=\mathrm{O})$ que ocorre em 1720-1740 $\mathrm{cm}^{-1}$, sofre deslocamento para $1575 \mathrm{~cm}^{-1}$, devido às interações com a superfície zeolítica. São observadas também, bandas de estiramentos $v \mathrm{C}-\mathrm{H}$, entre $1400-1300 \mathrm{~cm}^{-1}$, menos afetadas pelas interações com a zeólita [39].

A curva termogravimétrica (Fig. 3-I-A) indica que a zeólita na forma ácida, quando submetida a aquecimento sob atmosfera oxidante, possui um comportamento muito regular, apresentando estabilidade quanto às perdas de massa em até cerca de $250{ }^{\circ} \mathrm{C}$, e que apenas em $336{ }^{\circ} \mathrm{C}$ culmina com a perda de $5,4 \% \mathrm{~m} / \mathrm{m}$ de sua massa inicial, voltando a se estabilizar a partir de $350{ }^{\circ} \mathrm{C}$, como demonstra a sua derivada (Fig. 3-II-A). Essa redução de massa tem sido atribuída às águas intrazeolíticas.

No entanto, quando os cristais zeolíticos contêm moléculas de glutaraldeído ancoradas em sua superfície,

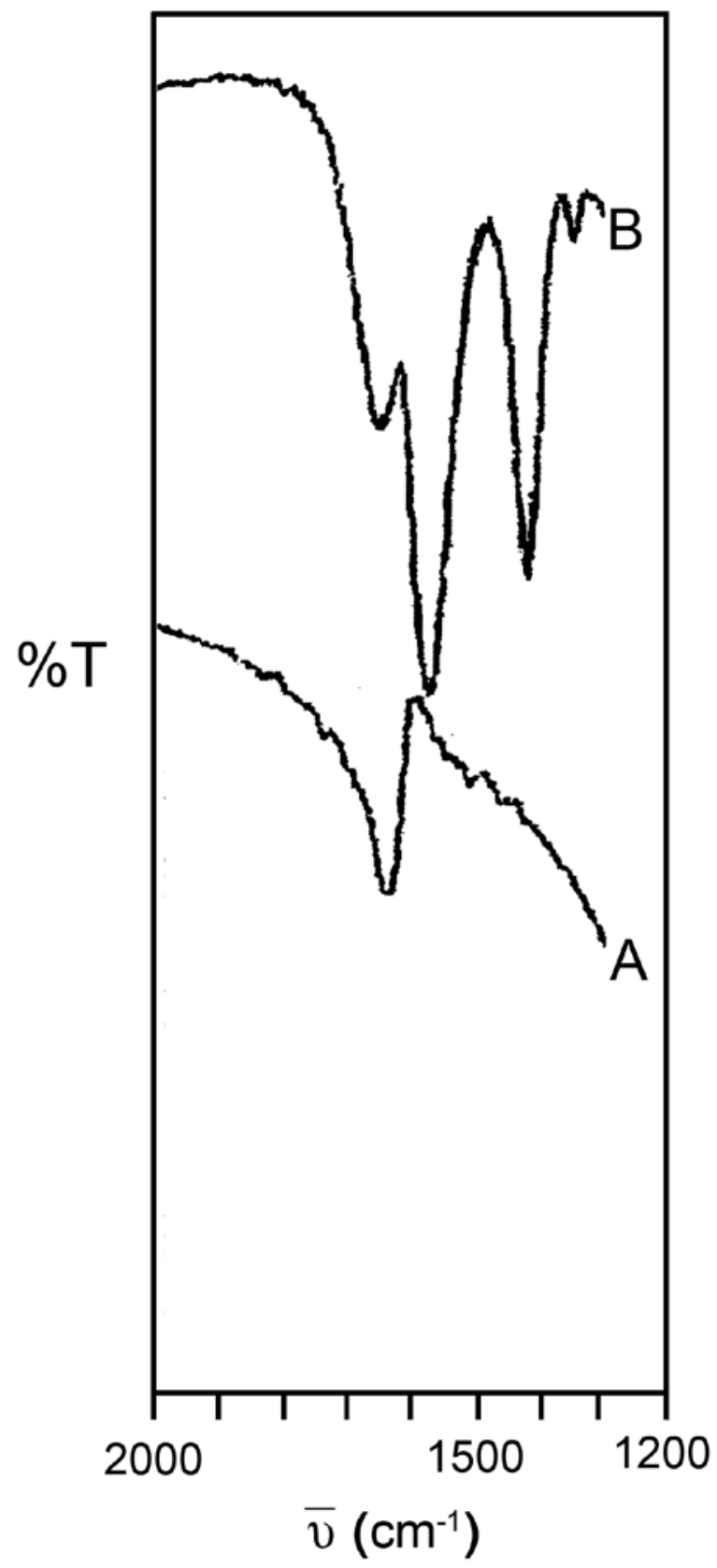

Figura 2: Espectros na região do infravermelho da zeólita analcima. (A) H-ANA, (B) H-ANA/Glu.

[Figure 2: FTIR spectra of analcime zeolite. (A) $H$-ANA, (B) $H$ $A N A / G l u$.

a curva termogravimétrica (Fig. 3-I-B) passa a apresentar um deslocamento de cerca de $100{ }^{\circ} \mathrm{C}$ na temperatura de perda de massa que foi de $8,7 \% \mathrm{~m} / \mathrm{m}$. Isto aponta para dois possíveis efeitos, um incremento na estabilidade térmico do glutaraldeído ancorado, e a termodessorção em um só estágio, como mostra a curva de DTG (Fig. 3-II-B), corroborando com os resultados da termovolatilização com análises no infravermelho (Fig. 4).

$\mathrm{O}$ processo seguinte, identificado apenas na curva 


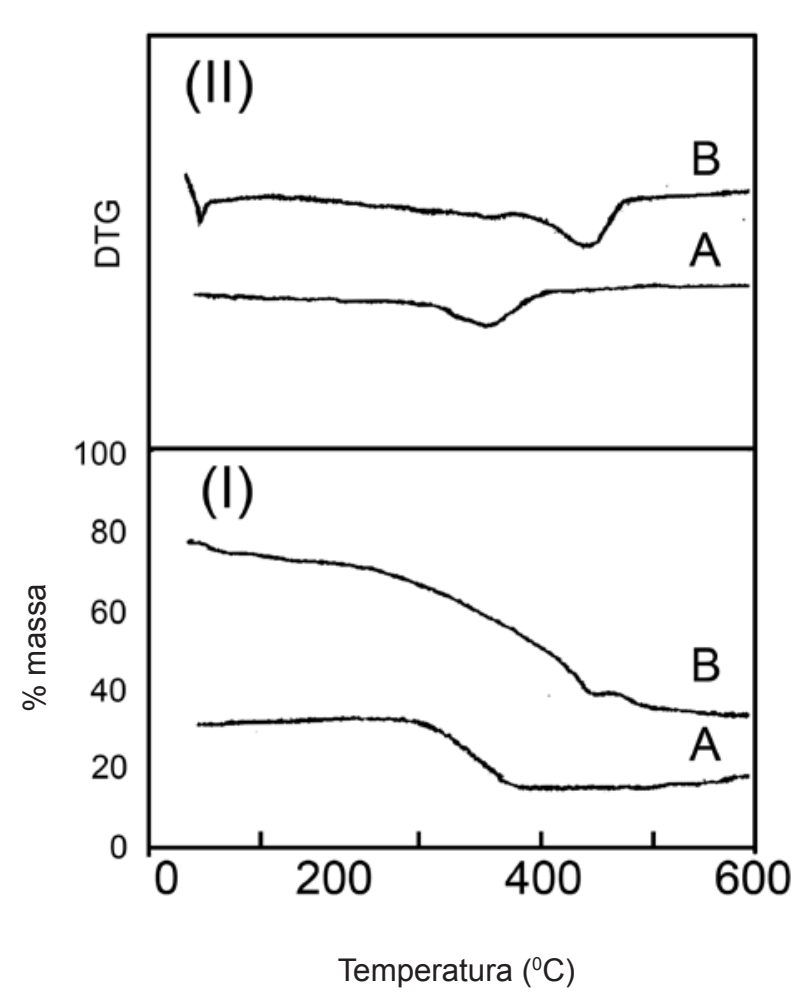

Figura 3: Curvas termogravimétricas TGA(I) e DTG(II). (A) HANA, (B) H-ANA/Glu.

[Figure 3: Thermogravimetric curves TGA(I) e DTG(II). (A) $\mathrm{H}$ ANA, (B) $H-A N A / G l u$.

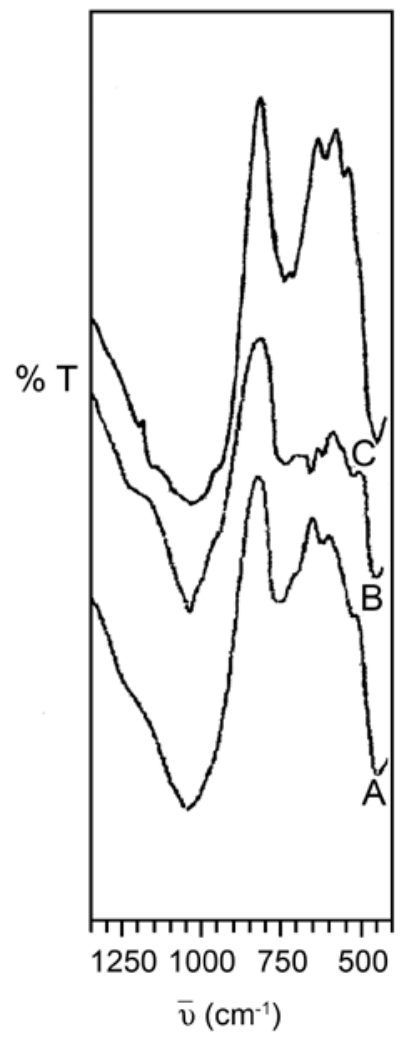

Figura 4: Espectros de absorção na região do infravermelho da zeólita analcima. (A) H-ANA, (B) H-ANA/Glu, (C) Resíduo sólida da termovolatilização.

[Figure 4: FTIR spectrum of analcime zeolite. (A) H-ANA, (B) $H$-ANA/Glu, (C) Thermovolatilization solid residue.]

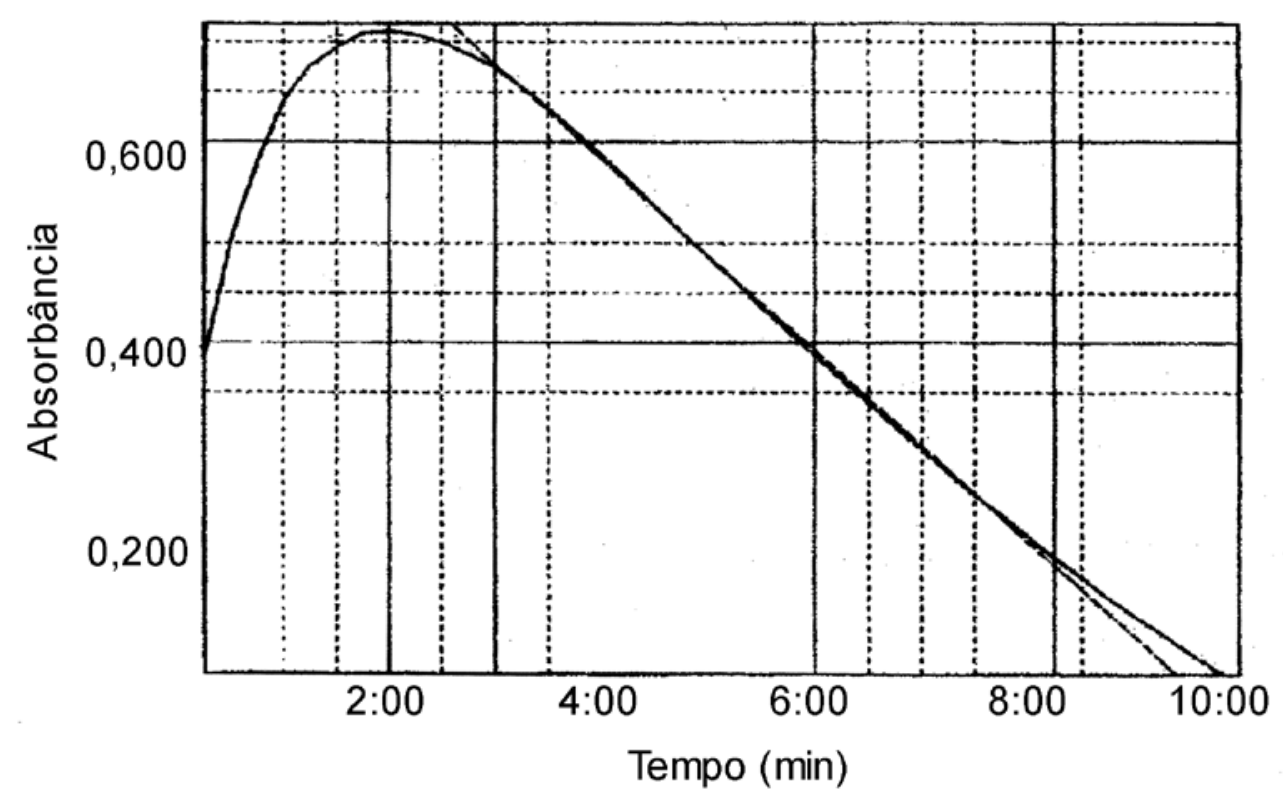

Figura 5: Espectro de absorção UV-VIS a $595 \mathrm{~nm}$ em função do tempo utilizando o reagente de Bradford. [Figure 5: UV-Vis spectrum at $595 \mathrm{~nm}$ versus time using Bradford reactant.] 


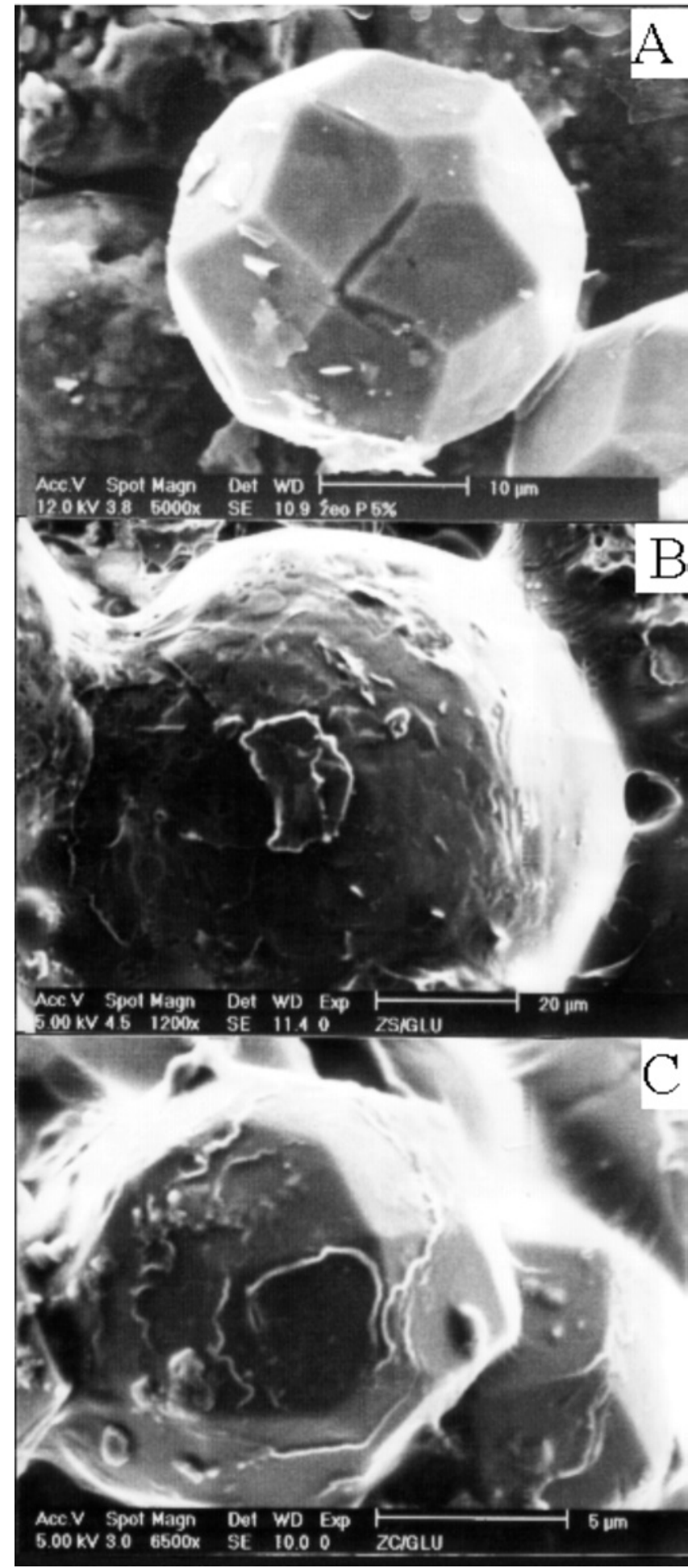

Figura 6: Imagens de microscopia eletrônica de varredura da zeólita analcima contendo o extrato proteico. (A) Analcima, (B) Analcima antes da funcionalização com glutaraldeído, (C) Analcima após a funcionalização com glutaraldeído.

[Figure 6: Scanning electron microscopy micrographs of analcime zeolite with proteic extract. (A) pure anacime, (B) before glutaraldehyde funcionalization, $(C)$ after glutaraldehyde funcionalization.] termogravimétrica do material contendo glutaraldeído (Fig. 3B), ocorre em aproximadamente $437{ }^{\circ} \mathrm{C}$, relativo a uma redução de massa de $8,7 \%$, que tem sido atribuída à decomposição do glutaraldeído. Essa decomposição, no entanto, ocorre em uma única etapa, que através da termovolatilização com análises no infravermelho (Fig. 4) evidencia-se a sua saída sem que este tenha sofrido pirólise.

A quantidade de proteínas totais encontradas no extrato bruto utilizando o método de Bradford [31] (Fig. 5) foi de $1,763 \mathrm{mg}$ para cada $100 \mathrm{~mL}$ de extrato protéico bruto.

O efeito do glutaraldeído sobre a imobilização do extrato protéico é bem visível quando observado através das imagens geradas por microscopia de varredura eletrônica (Fig. 6), que por estimativa, tem-se uma diferença de cerca de 6 vezes na espessura da camada protéica condensada na superfície da zeólita. Para a condensação na superfície sem o glutaraldeído, observa-se um incremento na espessura dos cristais da ordem de $6,0 \times 10^{-4} \mathrm{~mm}$.

No entanto, quando a condensação é feita na superfície funcionalizada com o glutaraldeído, nota-se um aumento de apenas $1,0 \times 10^{-4} \mathrm{~mm}$ na espessura do material. Este efeito tem sido atribuído ao glutaraldeído, que conforme mostrou o espectro de infravermelho do produto da termovolatilização (Fig. 4), o mesmo interage com a superfície da zeólita preservando grupos funcionais para uma segunda coordenação. Esta estaria interagindo através das carbonilas remanescentes, sobre as estruturas protéicas de maneira seletiva, permitindo que apenas certos tipos de proteínas interajam, no caso, a PPO presente no extrato protéico. Já a superfície sem glutaraldeído tendo somente sítios ácidos, não apresentaria qualquer comportamento seletivo frente aos diversos tipos de proteínas contidas no extrato, daí a formação de uma espessa camada sobre a zeólita.

\section{CONCLUSÕES}

A adsorção de glutaraldeído é dependente da natureza ácida da superfície zeolítica, pois não demonstrou nenhuma afinidade pela espécie não tratada com o ácido clorídrico. A presença de glutaraldeído resultou num efeito seletivo das espécies químicas presentes no extrato proteico, que pode ser comprovado pela formação de uma fina camada. Já na ausência de glutaraldeído ocorreu a formação de uma espessa camada protéica. Portanto a utilização desse espaçador, é fundamental para que se tenha uma adsorção seletiva de proteínas em suportes como as zeólitas, por exemplo.

\section{AGRADECIMENTOS}

Os autores agradecem à Capes pela bolsa de estudos de Silva Gondim, à FUNCAP e UFC, e ao Prof. Igor Vasconcelos pelas análises de microscopia eletrônica. 


\section{REFERÊNCIAS}

[1] D. W. Breck, Zeolite Molecular Sieves, John Wiley \& Sons, Malabar, Florida (1974).

[2] R. M. Barrer, J. Soc. Chem. Ind. (1956) 2882.

[3] R. M. Barrer, J. Chem. Soc. (1948) 2158.

[4] D. W. Breck, R. M. Milton, T. B. Read, T. L. Tomas, J. Am. Chem. Soc. 78 (1956) 5963.

[5] M. L. S. Corrêa, M. Wallau, U. Schuchardt, Química Nova 19 (1996) 43.

[6] C. D. Chang, Catal. Ver. Sci. Eng. 24 (1983) 1.

[7] Y. W. Chen, K. K. Kohn, Y. M. Wang, J. Chim. Inst. Chem. Eng. 31 (2000) 123.

[8] M. Anpo, H. Yamashita, K. Ileue, Y. Fujii, S. G. Zhang, Y. Ishihashi, D. R. Park, Y. Suzuki, K. Koyano, T. Tatsumi, Catal. Today 44 (1998) 327.

[9] M. Krug, M. Jaroniec, R Ryoo, S. H. Joo, Chem. Mater. 12 (2000) 1414.

[10] R. Tsumura, S. Higashimoto, M. Matsuoka, H. Yamashita, M. Che, M. Anpo, Catal. Letter 68 (2000) 101.

[11] M. Davis, Proc. Int. Conf. on Inovation in Zeolite Science, Newpoort, Belgium, (1997).

[12] R. Kikuchi, Res. Conser. Recicl. 27 (1999) 333.

[13] J. P. Bellat, O. Bertrand, F. Bouvier, Mater. Envirom. Friendy Proc. 125 (1999) 737.

[14] M. E. Tess, J. A. Cox, J. Pharm. Biomed. Anal. 2 (1999) 55.

[15] A. Walcarius, Anal. Chim. Acta 384 (1999) 1.

[16] R. W. Murray, R. A. Ewing, Anal. Chem. 59 (1987) 300 .

[17] L. C. Clarck, L. Lyons, Ann. Acad. Sci. 102 (1962) 29.

[18] P. Kunaram, Y. L. Paruchi, Water Res. 31 (1997) 11.

[19] G. Ferraris, J. Yerkess, D. W. Jones, Z. Kristallogr. Krist. 135 (1972) 240.

[20] L. R. D. da Silva, Y. Gushikem, L. T. Kubota, Colloid and Surface B.: Biointerface 6 (1996) 309.
[21] K. Adachi, T. Hirata, N. Fujisawa, M. Sakagushi, Fish. Sci. 65 (1999) 926.

[22] A. M. Mayer, E. Harel, Phytochem. 18 (1979) 193.

[23] D. E. Fenton, Biocoordination Chemical, Oxford University Press, London, (1995).

[24] A. Kondo, F. Murakami, M. Kawagoe, Appl. Microb. Biotech. 39 (1998) 726.

[25] K. Matsumoto, H. Kamidado, Y. Osajima, Anal. Chem. 60 (1988) 147.

[26] J. Ruzicka, E. H. Hansen, Anal. Chim. Acta 106 (1997) 207.

[27] O. F. Fatibello, M. D. Capelato, Química Nova 15 (1992) 28.

[28] A. C. S. Gondim, P. de Lima Neto, L. R. D. da Silva, An. Ass. Bras. Quím. 50 (2001) 1761.

[29] P. C. Lopes, F. A. Dias, L. R. D. da Silva, Mater. Lett. 57 (2003) 3397.

[30] J. F. Kennedy, J. M. S. Cabral, Trans. Met. Chem. 12 (1987) 481.

[31] M. M. Bradford, Anal. Biochem. 72 (1976) 248.

[32] D. Nibou, B. Abbad, A. Azzouz, Amer. J. Chim. Phys. 88 (1991) 2371.

[33] Y. Yokomori, S. Idaka, Microporous Mesoporous Mater. 21 (1998) 365.

[34] F. Pechar, Zeolites 8 (1998) 247.

[35] M. E. Davis, Ind. Eng. Chem. Rev. 30 (1991) 1675.

[36] V. B. Kanzansky, P. A. Jacobs, N. I. Jae, P. Jiru, G. Schulz-Ekloff, Structure and reactivity of modified zeolites, Elsevier, New York (1984).

[37] G. Mirth, J. A. Lercher, J. Phys. Chem. 95 (1991) 3736.

[38] M. H. W. Sonnemans, D. Heijer, M. Crocker, J. Phys. Chem. 97 (1993) 440.

[39] R. Dyer, Applications of Absortion Spectroscopy of Organic compounds, Prentice-Hall, London (1965).

(Rec. 04/02/2003, Rev. 24/06/05, Ac. 30/06/2005) 